\title{
The IUCN Wild Pig Challenge 2015
}

\author{
Matthew Linkie, Jasline Ng, Zhi Qi Lim, Muhammad I. Lubis \\ MARK RADEMAKer and ERIK MEIJAard
}

\begin{abstract}
Asian mammal species are facing unprecedented pressures from hunting and habitat conversion. Efforts to mitigate these threats often focus on charismatic large-bodied species, while many other species or even guilds receive less attention, particularly Asian wild pigs. To address this we developed a rapid questionnaire survey and administered it to relevant experts to identify the presence, population trends and conservation needs of Asia's 11 threatened wild pig species. The results highlighted geographical differences within species (e.g. the near collapse of bearded pig populations in Peninsular Malaysia yet their widespread presence on Borneo), and knowledge gaps for many endemic species of the Philippines, notably the Critically Endangered Visayan warty pig Sus cebifrons. To support field-based conservation projects, we identified 66 medium-to-large zoos in Asia, Europe and the USA that house Asian wild pigs and have applicable conservation funding schemes. Our rapid survey method, which yielded 170 wild pig records from across Asia, proved effective in filling many of the existing knowledge gaps, and may be widely applicable in assessing the status and needs of other non-flagship threatened species.
\end{abstract}

Keywords Habitat loss, hunting, Indonesia, Malaysia, Philippines, Suidae

\footnotetext{
sian wild pigs suffer from an image problem. Few consider them to be as charismatic as orang-utans Pongo spp., elephants Elephas maximus and other Asian flagship species. They have names such as warty pig (referring to the noticeable lumps across the face) and bearded pig (referring to the bushy muzzle exhibited by males and females). Yet like the tiger Panthera tigris and snow leopard Panthera uncia they can be considered enigmatic. The Sunda bearded pig Sus barbatus is unique in being South-east Asia's only terrestrial migratory mammal species. It follows mast fruiting events in the forest and traverses hundreds, sometimes thousands, of kilometres. In

Matthew LinkiE* (Corresponding author), MARK RADEMAKER $\dagger$ and ERIK MeIJAARD $\ddagger$ IUCN/SSC Wild Pig Specialist Group. E-mail mlinkie@wcs.org JasLine NG and Zhi Qi Lim National University of Singapore, Singapore

Muhammad I. Lubis Wildlife Conservation Society, Indonesia

${ }^{*}$ Also at: Wildlife Conservation Society, Indonesia

$\dagger$ Also at: Bawean Endemics Conservation Initiative, Indonesia

\$Also at: Borneo Futures, Brunei Darussalam

Received 10 March 2016. Revision requested 6 May 2016.

Accepted 16 May 2016. First published online 28 September 2016.
}

Sumatra it is often referred to as lumba lumba (Indonesian for dolphin) because local people believe that when sounders of up to 100 foraging pigs disappear from a forest patch they turn into dolphins and swim to the sea. Also, because of their importance to many communities, wild pigs are considered to be cultural keystone species.

The IUCN/SSC Wild Pig Specialist Group seeks to raise the profile of wild pigs, draw attention to their plight and support conservation interventions. Of the 17 extant pig species in the Suidae family, 13 occur in Asia and 11 of these are threatened with extinction (categorized as Vulnerable, Endangered or Critically Endangered on the IUCN Red List; IUCN, 2016), mainly as a result of hunting and loss of forest habitat. The remaining two species, Sus celebensis and Sus scrofa, are categorized as Near Threatened and Least Concern, respectively. For most of these species there is a lack of dedicated research and conservation management attention, and therefore their status is poorly known. Yet they have a worldwide presence in zoos, which also have conservation funding schemes that could be used to support in situ efforts if the conservation priorities were better understood. To start addressing this knowledge gap we developed the Wild Pig Challenge 2015, a series of succinct questions on the status of Asian wild pigs, the threats they face, and conservation opportunities ( $\mathrm{Ng}$ et al., 2015). The questionnaire was intentionally short (to be completed in $<5$ minutes) to elicit a greater response. We targeted members of the Wild Pig Specialist Group and other relevant Specialist Groups, such as Asian Wild Cattle, Asian Elephant and Galliformes, as well as academic researchers and ornithologists, who often visit sites that overlap with pig species.

The first set of questions was sent via a group e-mail to $>50$ experts, with a request for them to forward to other relevant experts. This meant that we were unable to track the exact number of people contacted. The questions focused on species status (presence/absence and population trend), and we received 107 individual responses, of which nearly $80 \%$ were provided within the first 3 days. Following a second group e-mail the total increased to 170 individual species-level responses. These also included data from Warty Watch, an expert-based survey focused on recording presence of the Javan warty pig Sus verrucosus (Rademaker, 2015). Excluding Sus scrofa (as a nonthreatened wild pig species), we reported on the following countries and species:

- India ( $\mathrm{n}=3$ country-level responses): pygmy hog Porcula salvania (3 species-level responses) 


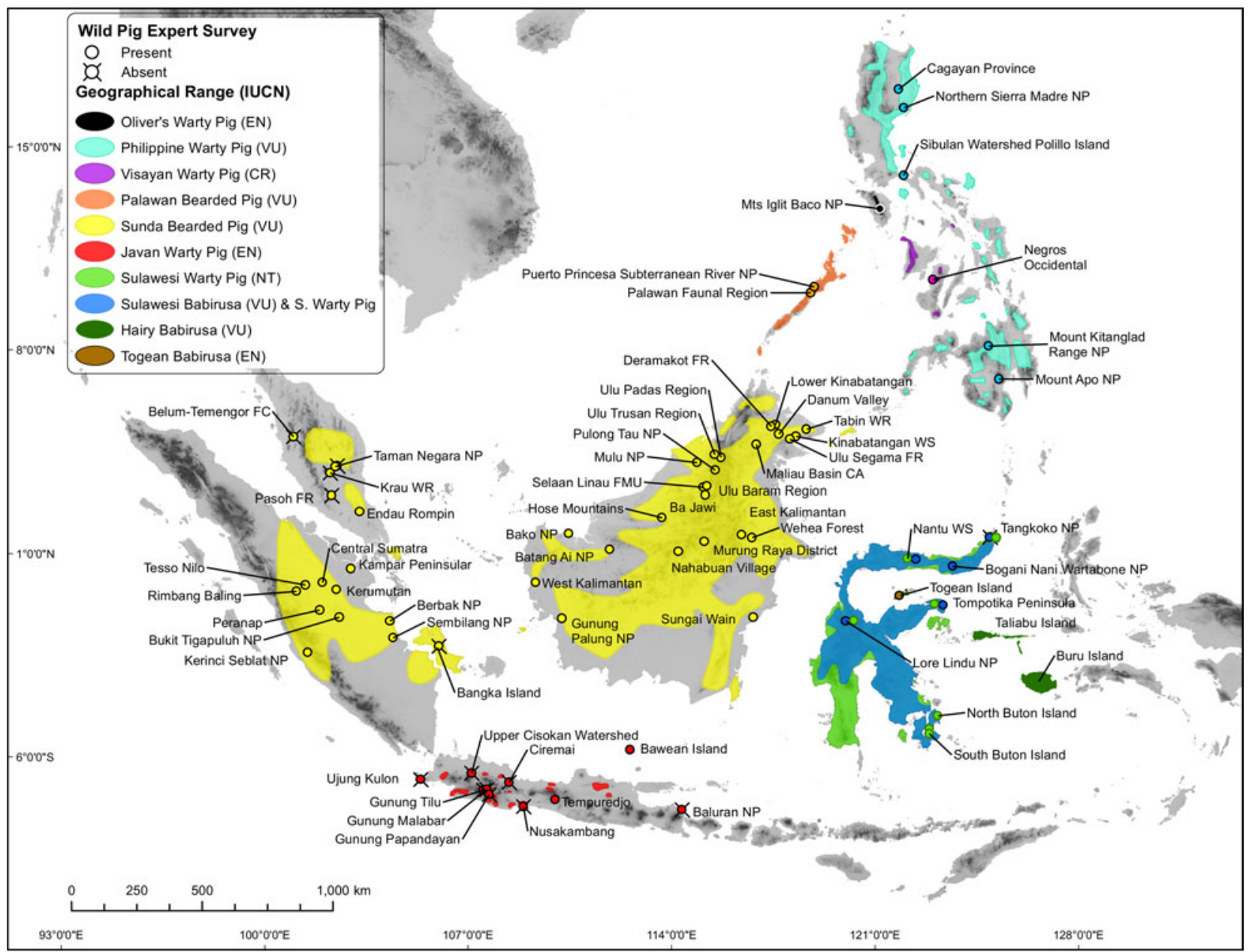

Fig. 1 Results from the Wild Pig Challenge 2015, with presence or absence of South-east Asian wild pigs according to expert opinion, and IUCN species range data.

- Indonesia (49): Sulawesi babirusa Babyrousa celebensis (5), Sulawesi warty pig Sus celebensis (8), Sunda bearded pig (21), Bawean warty pig/Javan warty pig (12), Togean babirusa Babyrousa togeanensis (1) and hairy babirusa Babyrousa babyrussa (2)

- Malaysia (31): Sunda bearded pig (31)

- Philippines (9): Mindoro warty pig Sus oliveri (1), Palawan bearded pig Sus ahoenobarbus (2), Philippines warty pig Sus philippensis (5), Visayan warty pig Sus cebifrons (1)

Based on survey feedback we mapped the presence and absence of the South-east Asian wild pig species (Fig. 1). Most (64\%) respondents were unsure of species population trends or perceived them to be decreasing (22\%). The only response for Visayan warty pig indicated an increasing trend, whereas only one of 52 responses for bearded pigs indicated that populations were increasing. The species-specific data yielded the following results.

Sunda bearded pig (Vulnerable; 52 records from respondents, of which $90 \%$ indicated presence) Species presence was reported from only one (Endau Rompin) of six sites in
Peninsular Malaysia, which follows on from a previous study that documented this decline (Kawanishi et al., 2013). A single respondent with long-term experience from the small Indonesian island of Bangka indicated that bearded pigs were no longer present on the island, which was probably only ever a peripheral part of the species' range, but we did record S. scrofa there. The species was reported to be widespread in Borneo, although more records are needed from Kalimantan (Indonesian Borneo), which was underrepresented in our survey.

Javan warty pig (Endangered; 2 of 12 records indicated presence) Species presence was reported from only one of eight sites in mainland Java. Java has one of the highest human population densities $\left(1,121\right.$ people $\left.\mathrm{km}^{-2}\right)$ in the world and many large-bodied mammal species have been extirpated (e.g. Javan tiger Panthera tigris sondaica) or are at risk of extinction (e.g. Javan leopard Panthera pardus melas and banteng Bos javanicus). That the Javan warty pig is reported to occur in Tempuredjo is encouraging. The remoteness of Bawean island, c. $120 \mathrm{~km}$ from mainland Java, affords a level of protection to the resident warty pigs, which are the 
only known viable wild population, underlining the importance of forest and species protection on the island.

Sulawesi babirusa (Vulnerable; 4 of 5 records indicated presence) Reports largely confirm the little that is known about the species; it remains widespread on Sulawesi but is under high hunting pressure (Milner-Gulland \& Clayton, 2002).

Hairy babirusa (Vulnerable; o of 2 records indicated presence) No records were found from the islands of Taliabu or Buru, although these reports are both from a single source (Eaton \& Hutchinson, 2015). Surveys on both islands are now a priority for the Wild Pig Specialist Group.

Togean island babirusa (Endangered; 1 of 1 record indicated presence) Although from a smaller island than the Moluccan (hairy) babirusa, reported species presence was confirmed. Recent unpublished population estimates indicate that several hundred Togean babirusas may remain and this may be among the largest populations of all three babirusa species (Macdonald et al., 2016).

Sulawesi warty pig (Near Threatened; 8 of 8 records indicated presence) This species was reported to be widespread, despite high hunting pressure from the predominantly Christian population of Sulawesi (Milner-Gulland \& Clayton, 2002).

Visayan warty pig (Critically Endangered; 1 of 1 record indicated presence) There was a report of an increase in the Visayan warty pig population on Negros island. However, we were unable to ascertain its status on the islands of Panay and Masbate, which IUCN includes in the species' range.

Palawan bearded pig (Vulnerable; 2 of 2 records indicated presence) There were two positive presence records for this species from the single island (Palawan) where it occurs.

Philippine warty pig (Vulnerable; 5 of 5 records indicated presence) This relatively wide-ranging species was reported at the northern (Luzon) and southern (Mindanao) parts of its range but there were no reports from the Visayas islands.

Oliver's/Mindoro warty pig (Endangered; 1 of 1 record indicated presence) This range-restricted species was reported to be present on Mount Iglit Baco on Mindoro, the only island where it is known to occur.

Pygmy hog (Critically Endangered; 3 of 3 records indicated presence) Presence was reported in the national parks of Manas, Nameri and Orang.

After the first survey we administered a second set of questions that aimed to identify threats and the conservation actions required to mitigate these threats. A second group e-mail was sent to the same list of experts whom we contacted in the first survey, but this elicited a lower response (35 responses, plus four that were excluded because they related to non-Asian pig species). From this we identified existing in situ conservation actions, other conservation actions with indirect benefits, top conservation action priorities, and interest in conducting specific conservation actions for Asian wild pigs.

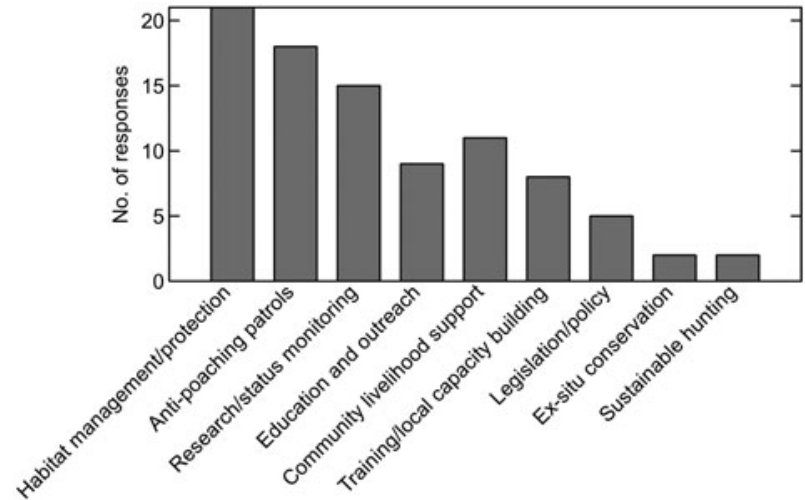

FIG. 2 Conservation priorities for Asian wild pig species, identified through an expert-based opinion survey $(n=35)$.

According to the responses there are existing in situ conservation actions $(\mathrm{n}=5)$ in Indonesia and India. Conservation research focused specifically on warty pigs on Bawean island has been conducted by Bawean Endemics Conservation Initiative and there are plans to introduce conservation education activities on the island. More generally, forest reserves on Buton Island (Sulawesi) and an IndoMet Coal concession (Central Kalimantan) have local bans on hunting of wild pigs, which for the latter applies to all of its employees and contractors. However, despite the ban on Buton Island the respondent noted that hunting is still widely practised there. In India the Pygmy Hog Conservation Programme appears to be making progress, with conservation activities across several sites.

Compared to specific conservation actions with direct benefit, there were more conservation actions $(n=23)$ that were considered to be benefiting Asian wild pig species indirectly. These responses came from Malaysia (9), Indonesia (8), India (3), Cambodia (2) and the Philippines (1). The majority of responses $(57 \%)$ cited habitat protection (via protected areas) at project sites as the conservation action benefiting Asian wild pigs. Some responses mentioned that habitat protection was put in place specifically for tigers, elephants and orang-utans. The most critical conservation actions cited for Asian wild pigs were habitat management, anti-poaching patrols, and research/species status monitoring (Fig. 2). Nearly half (17 of 35) of respondents expressed interest in implementing conservation actions rather than just conducting research.

Seeking means to support ongoing conservation projects or stimulate new projects for wild pig conservation, we conducted an internet search for medium-to-large zoos in Asia (India, Singapore and Malaysia), Europe and the USA that housed wild pig species and had conservation funding schemes. We identified 66 zoos from 14 countries with five Asian wild pig species (S. scrofa excluded; Table 1). Of these zoos, nearly half $(49 \%)$ had conservation funding schemes but none specifically for wild 
TABLE 1 Summary of medium-to-large zoos in Asia, Europe and the USA with Asian wild pig species and conservation funding schemes.

\begin{tabular}{|c|c|c|c|c|c|}
\hline \multirow[t]{2}{*}{ Species } & \multicolumn{2}{|c|}{ No. of zoos surveyed ${ }^{1}$} & \multirow[t]{2}{*}{ Potential funding } & \multicolumn{2}{|c|}{ Support for wild pigs } \\
\hline & $\begin{array}{l}\text { Housing } \\
\text { species }\end{array}$ & $\begin{array}{l}\text { Supporting pig } \\
\text { conservation }^{2}\end{array}$ & & In situ & Ex situ \\
\hline Sunda bearded pig Sus barbatus & 8 & 1 & 7 & 1 & 1 \\
\hline Javan warty pig Sus verrucosus & 1 & 1 & 1 & 1 & 1 \\
\hline Sulawesi babirusa Babyrousa celebensis & 18 & 0 & 13 & 9 & 1 \\
\hline Sulawesi warty pig Sus celebensis & None found & & & & \\
\hline Visayan warty pig Sus cebifrons & 48 & 0 & 22 & 19 & 7 \\
\hline Palawan bearded pig Sus ahoenobarbus & None found & & & & \\
\hline Philippine warty pig Sus philippensis & None found & & & & \\
\hline Oliver's/Mindoro warty pig Sus oliveri & None found & & & & \\
\hline Pygmy hog Porcula salvania & 1 & 1 & 1 & 0 & 1 \\
\hline
\end{tabular}

${ }^{1}$ Some zoos host more than one species, and therefore numbers in table may not completely match those in the main text.

${ }^{2}$ Zoos that fund pig conservation but do not house the species.

pigs. Some $(47 \%)$ zoos supported wild pig projects, either in situ (30 zoos) or ex situ (11). From our survey, the Visayan warty pig was most represented in zoos, followed by the Sulawesi babirusa. We uploaded the data on the zoos and their funding schemes to the Wild Pig Specialist Group website (2016).

Expert-based opinion surveys are commonly used for mapping species occurrence (e.g. Johnson \& Gillingham, 2004) and ascertaining threat status (Donlan et al., 2010). A main limitation may arise through varying levels of bias and expertise among respondents (Martin et al., 2012). This seems relevant regarding population trends, for which more in-depth knowledge and longer-term experience are required, and probably explains why most experts in our study were unable to comment on species trends. Although it is difficult to quantify uncertainty, we believe that the rapid survey method yielded useful results on species presence, based on our own knowledge, developed from having visited the relevant sites, known people who had visited recently, or being familiar with literature on these sites. The results provided insights into the state of Asian wild pigs at a regional scale. The resulting map will provide the basis for future Wild Pig Specialist Group discussions on prioritizing more detailed site-specific studies, and we are following up with several respondents regarding subsequent contributions to species status based on their future expeditions. This highlights another advantage of our approach. By contacting a wide variety of experts who are working on overlapping non-pig species we expanded our network of contacts with valuable knowledge on wild pig habitats. Our rapid questionnairebased approach has wide application and may, for example, be used to update the status of wild pig species in Africa and peccary species in Latin America, as well as increasing knowledge exchange between Specialist Groups and other field experts.

\section{Acknowledgements}

We thank the IUCN/SSC Specialist Group chairs, their members and other taxonomic experts who provided valuable information on the Asian wild pig species.

\section{References}

Donlan, C.J., Wingfield, D.K., Crowder, L.B. \& Wilcox, C. (2010) Using expert opinion surveys to rank threats to endangered species: a case study with sea turtles. Conservation Biology, 24, 1586-1595.

Eaton, J. \& Hutchinson, R.O. (2015) Surveys on Buru and Taliabu fail to reveal sign of babirusa. Suiform Soundings, 14, 27-28.

IUCN (2016) The IUCN Red List of Threatened Species v. 2015-4. Http://www.iucnredlist.org [accessed 9 June 2016].

Johnson, C.J. \& Gillingham, M.P. (2004) Mapping uncertainty: sensitivity of wildlife habitat ratings to expert opinion. Journal of Applied Ecology, 41, 1032-1041.

Kawanishi, K., Gopalasamy, R.C., Gumal, M., Goldthorpe, G., YASAK, M.N. \& SHARMA, D.S.K. (2013) Using BAD for good: how best available data facilitated a precautionary policy change to improve protection of the prey of the tiger Panthera tigris in Malaysia. Oryx, 47, 420-426.

Macdonald, A., Leus, K., Masaaki, I. \& Burton, J. (2016) Babyrousa togeanensis. The IUCN Red List of Threatened Species 2016: e.T136472A44143172. Http://dx.doi.org/10.2305/IUCN.UK. 2016-1.RLTS.T136472A44143172.en [accessed 9 June 2016].

Martin, T.G., Burgman, M.A., Fidler, F., Kuhnert, P.M., Low Choy, S., McBride, M. \& Mengersen, K. (2012) Eliciting expert knowledge in conservation science. Conservation Biology, 26, 29-38.

Milner-Gulland, E.J. \& Clayton, L. (2002) The trade in babirusas and wild pigs in North Sulawesi, Indonesia. Ecological Economics, $42,165-183$.

NG, J., Lim, Z.Q., Meijaard, E. \& Linkie, M. (2015) Update on the 'Wild Pig Challenge 2015'. Suiform Soundings, 14, 28-29.

RADEMAKER, M. (2015) 'Warty Watch': Putting the spotlight on Indonesia's most distinct pig. Suiform Soundings, 14, 14-21.

Wild Pig Specialist Group (2016) Https://sites.google.com/site/ wildpigspecialistgroup/iucnssc-wild-pig-specialist-group/researchand-conservation-priorities/funding-opportunities [accessed 15 September 2016]. 


\section{Biographical sketches}

Matthew Linkie is Asia Coordinator for the Wild Pig Specialist Group. Jasline NG and Zhi Qi Lim developed the questionnaire survey and analysed the response data through the National University of Singapore Environmental Studies Internship
Programme. Muhammad I. Lubis is a geographical information systems expert focusing on Sumatra. MARK RADEMAKER is cofounder of Bawean Endemics Conservation Initiative and a member of the Wild Pig Specialist Group focused on Javan and Bawean warty pigs. ERIK MeijaARD is the Chair of the Wild Pig Specialist Group. 